\title{
Morbidity related to defunctioning ileostomy closure after ileal pouch-anal anastomosis and low colonic anastomosis
}

\author{
Henderik L. van Westreenen • Annelies Visser • \\ Pieter J. Tanis • Willem A. Bemelman
}

Accepted: 28 June 2011 / Published online: 15 July 2011

(C) The Author(s) 2011. This article is published with open access at Springerlink.com

\begin{abstract}
Purpose Defunctioning ileostomies are widely performed in order to prevent or treat anastomotic leakage after colorectal surgery. The aim of the present study was to determine morbidity related to stoma closure and to identify predictive factors of a complicated postoperative course. Methods A consecutive series of 138 patients were retrospectively analyzed after stoma reversal. Data collection included general demographics and surgery-related aspects. Morbidity related to stoma closure was retrieved from our prospectively collected registry of complications.

Results In 74 of 138 patients, defunctioning ileostomy was performed after restorative proctocolectomy and ileal pouchanal anastomosis (IPAA). The remaining ileostomies $(n=64)$ were constructed after a low colorectal or coloanal anastomosis. A total of 46 complications were recorded in 28 patients resulting in an overall complication rate of $20.3 \%$. Anastomotic leakage rate was $4.3 \%$, and reoperation rate was $8.0 \%$. The number of complications according to the Clavien-Dindo classification was 5 for grade I (10.9\%), 26 for grade II (56.5\%), 13 for grade III (28.3\%), 1 for grade IV (2.2\%), and 1 for grade V (2.2\%). Multivariate analysis revealed a significantly higher ASA score in the complicated group $(P=0.015$, odds ratio $2.6,95 \%$ confidence interval 1.2-5.6).

Conclusions Closure of a defunctioning ileostomy is associated with $20 \%$ morbidity and a reoperation rate of $8 \%$. There
\end{abstract}

H. L. van Westreenen $(\bowtie) \cdot$ A. Visser $\cdot$ P. J. Tanis

W. A. Bemelman

Department of Surgery, Academic Medical Center,

Postbox 22660, 1100 DD Amsterdam, The Netherlands

e-mail: e.van.westreenen@antoniusziekenhuis.nl

H. L. van Westreenen

Department of Surgery, St. Antoniusziekenhuis,

Postbox 2500, 3430 EM Nieuwegein, The Netherlands is an urgent need for criteria on which a more selective use of a defunctioning ileostomy after low colonic anastomosis or IPAA can be based given its associated morbidity.

Keywords Defunctioning ileostomy · Stoma Ileostomy · Morbidity

\section{Introduction}

Defunctioning ileostomies are widely performed in order to prevent anastomotic leakage after colorectal surgery, especially anterior resection and restorative proctocolectomy with ileal pouch-anal anastomosis (IPAA) [1, 2]. A recent meta-analysis demonstrated a reduction of clinical anastomotic leakage rate after a defunctioning stoma leading to a reduction in the number of reoperations, but without significant decrease of mortality [3]. Besides, primary defunctioning loop ileostomies are constructed as treatment of anastomotic-related complications in the acute postoperative setting.

Although the potential benefits of an ileostomy are clear, the loop ileostomy itself is associated with significant morbidity affecting patients' daily activities. Stoma-related complications like prolapse, parastomal hernia, retraction, and high output occur in up to $30 \%$ of patients with a stoma $[4,5]$. In addition, stoma reversal is accompanied with substantial morbidity $(20 \%)$ which should be taken into account at the time of creation of a prophylactic stoma [6]. Most defunctioning stomas are for temporary fecal diversion, but a complicated clinical course following the initial colorectal operation is a limiting factor for stoma reversal resulting in a permanent stoma [7]. This retrospective study was performed to identify risk factors for complications after reversal of a defunctioning stoma to divert a low colonic anastomosis or IPAA. 


\section{Patients and methods}

From January 2004 to June 2010, 366 consecutive patients underwent elective colorectal surgery with primary rectal or anal anastomosis. All procedures were performed in the Academic Medical Center (AMC), a university hospital and tertiary referral center. Of the 366 patients, 204 patients underwent a proctocolectomy followed by IPAA, and the remaining 162 patients had an anterior resection or low anterior resection followed by a colorectal or coloanal anastomosis, respectively. A defunctioning stoma was created in 135 patients during the initial procedure. In an additional number of 32 patients, the primary operation had a complicated course, and a defunctioning stoma was created to treat anastomotic-related complications (Fig. 1). Of these 167 patients with a defunctioning stoma, closure was performed in $138(82.6 \%)$, and these patients were included in our retrospective analysis.

Patient data and surgery-related characteristics were retrospectively collected by retrieving medical records. Data collection included general demographics, primary diagnosis, indication for loop ileostomy, time from formation to closure, and operative technique of stoma closure. Morbidity related to stoma closure was retrieved from our prospective collected registry of complications of the surgical department of the AMC.

Closure of the loop ileostomy was mostly performed by a surgical resident under the direct supervision of a colorectal surgeon. The stoma was dissected from the mucocutaneous junction and delivered from the rectus sheath and peritoneal cavity by sharp dissection. The enterotomy was closed by a running suture or a stapled closure based upon the preferences of the supervising surgeon. The posterior and anterior rectus sheaths were closed separately to minimize the risk of an incisional hernia. The wound was partially left open to prevent wound infection.

Descriptive statistics were used for data analysis in presentation. Differences between groups were assessed for statistical significance $(P<0.05)$ using either chi-square test or Mann-Whitney $U$ test when appropriate. Subsequently, a stepwise multivariate analysis was performed using a forward conditional model. Statistical analysis was performed using the SPSS software package (SPSS 16.0, Chicago, IL, USA).

\section{Results}

In total, 138 defunctioning ileostomies were closed over the study period and included in this retrospective analysis. The group consisted of 80 male and 58 female patients with a mean age at closure of 49 years (Table 1). The majority of patients (65\%) had an American Society of Anesthesiology (ASA) score of 2 . The predominantly primary diagnoses of the patients were ulcerative colitis and colorectal cancer. The setting for construction of an ileostomy was elective in $79 \%$ and acute in $21 \%$ of the patients. Comparing these two groups of patients revealed that the acutely created stomas were closed significantly later (Table 2). Furthermore, these patients were predominantly operated on for inflammatory bowel disease. Almost all stomas were closed by a surgical resident under the supervision of a colorectal surgeon, mostly using a hand-sewn technique (Table 1). The median time interval between construction and stoma closure was 17 weeks.
Fig. 1 Of the 167 patients with a defunctioning stoma, closure was performed in 138

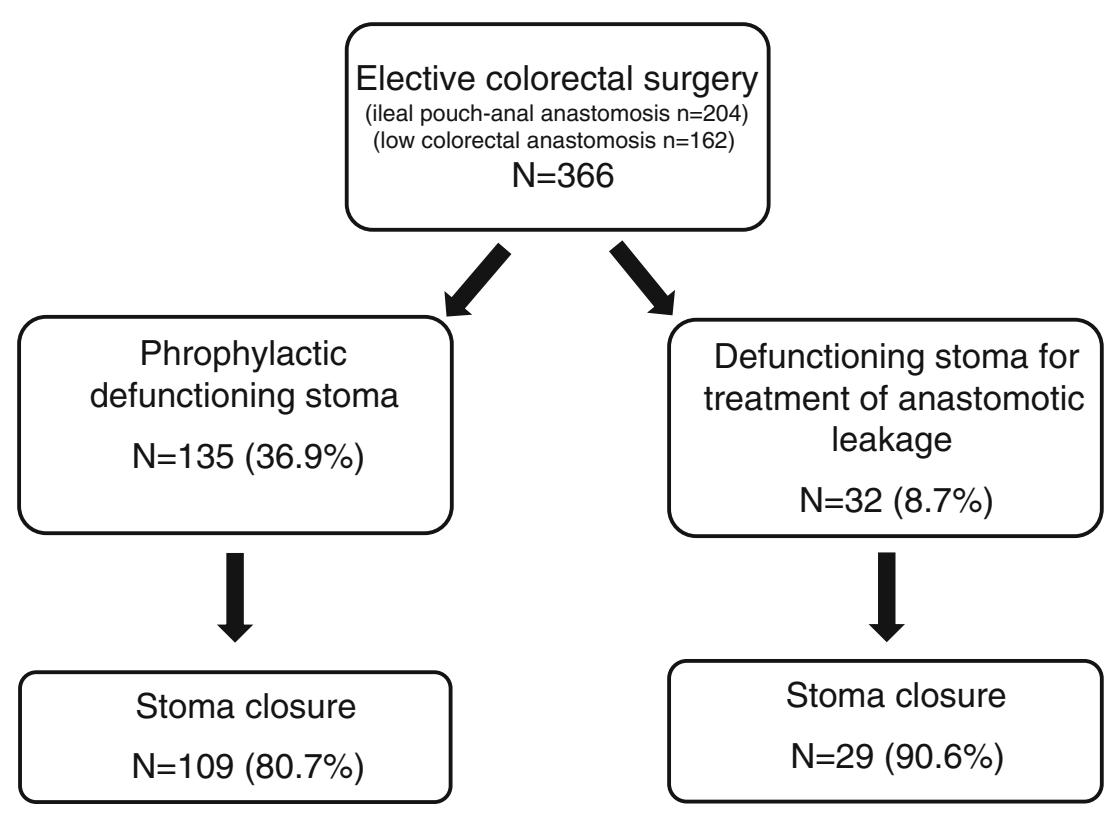


Table 1 Baseline characteristics of 138 patients undergoing closure of a defunctioning stoma

\begin{tabular}{|c|c|}
\hline Characteristics & Number $(\%)$ \\
\hline \multicolumn{2}{|l|}{ Sex } \\
\hline Male & $80(58.0)$ \\
\hline Female & $58(42.0)$ \\
\hline Age (years) ${ }^{\mathrm{a}}$ & $49.3(15.7)$ \\
\hline \multicolumn{2}{|l|}{$\mathrm{ASA}^{\mathrm{b}}$ class } \\
\hline I & $31(22.5)$ \\
\hline II & $90(65.2)$ \\
\hline III & $17(12.3)$ \\
\hline \multicolumn{2}{|l|}{ Diagnosis at initial surgery } \\
\hline Ulcerative colitis & $62(44.9)$ \\
\hline Colorectal cancer & $51(37)$ \\
\hline Familial adenomatous polyposis & $10(7.2)$ \\
\hline Crohn's disease & $5(3.6)$ \\
\hline Other & $10(7.2)$ \\
\hline \multicolumn{2}{|l|}{ Indication for defunctioning stoma } \\
\hline Ileal pouch-anal anastomosis & $74(53.6)$ \\
\hline Low colorectal or coloanal anastomosis & $64(46.4)$ \\
\hline \multicolumn{2}{|c|}{ Setting of construction of defunctioning stoma } \\
\hline Elective (prophylactic) & $109(79)$ \\
\hline Acute (anastomotic complications) & $29(21)$ \\
\hline \multicolumn{2}{|l|}{ Surgeon } \\
\hline Resident & $124(89.9)$ \\
\hline Colorectal surgeon & $14(10.1)$ \\
\hline \multicolumn{2}{|l|}{ Anastomotic technique } \\
\hline Hand-sewn & $123(89.1)$ \\
\hline Stapled & $15(10.9)$ \\
\hline Time to stoma closure (weeks) ${ }^{\mathrm{c}}$ & $16.9(0.9-70.6)$ \\
\hline Hospital stay $(\text { days })^{\mathrm{c}}$ & $5.0(2-67)$ \\
\hline
\end{tabular}

${ }^{\mathrm{a}}$ Mean (SD)

${ }^{\mathrm{b}}$ American Society of Anesthesiology

${ }^{\mathrm{c}}$ Median (range)

In three patients, stoma closure was performed simultaneously during liver resection for colorectal metastases.

Twenty-eight patients $(20.3 \%)$ had a complicated course, consisting of a total of 46 complications (Table 3). The anastomotic leakage rate was $4.3 \%$. The Clavien-Dindo grade of complications was grade I in $10.9 \%(n=5)$, grade II in $56.5 \%(n=26)$, grade III in $28.3 \%(n=13)$, grade IV in $2.2 \%(n=1)$, and grade $\mathrm{V}$ in $2.2 \%(n=1)$. Readmission rate within 30 days after stoma closure was $3.6 \%$ of the patients, predominantly for rehydration or treatment for small bowel obstruction. In one patient, stoma reversal was combined with dilatation of the colorectal anastomosis resulting in perforation requiring reoperation. Seventeen reoperations were performed in 11 patients $(8.0 \%)$, and construction of an ileostomy was necessary again in eight patients $(5.8 \%)$
(Table 3). One patient had a massive bleeding from the epigastric artery leading to multiple organ failure and eventually death. This accounts for a mortality rate of $0.7 \%$.

To identify risk factors for the development of complications after loop ileostomy closure, potentially related variables were compared between the group of 110 patients with an uncomplicated course and the group of 28 patients with a complicated course (Table 4). Univariable analysis revealed that the complicated group had a significant higher age and a higher ASA score in comparison to the group without complications. No significant association with a complicated postoperative course was found for gender, primary diagnosis, type of primary surgery, setting of stoma creation (elective versus acute), surgeon, time to stoma closure, or anastomotic technique. Multivariate analysis revealed a higher ASA score as the only predictor for a complicated course after stoma reversal $(P=0.015$, odds ratio $2.6,95 \%$ confidence interval $1.2-5.6)$.

\section{Discussion}

Loop ileostomy closure is accompanied by a substantial morbidity and even a small risk of mortality as demonstrated by the present study. This analysis comprised both electively and acutely created ileostomies, in contrast to previous studies which only focussed on the elective setting. The overall complication rate of $20 \%$ fits well within the morbidity rates as reported in the literature (11$37 \%$ ) $[6,8-10]$. A reoperation was necessary in $8 \%$ which is higher as reported in a recent systematic review concerning stoma reversal [6]. However, this review reported a reoperation rate of $2.5 \%$ for small bowel obstruction only. Therefore, $8 \%$ of reoperations might be more realistic as they reflect the overall percentage for several postoperative complications as was demonstrated by Mansfield et al. [11].

Small bowel obstruction was the most frequent complication (6.5\%) and responsible for the majority of readmissions. Edema of a narrowed anastomosis may cause a small bowel obstruction in the postoperative period. Previous reports suggested that a stapled closure might prevent small bowel obstruction due to the larger bowel lumen that is created [12]. However, a recent meta-analysis did not demonstrate differences in clinical outcome between handsewn and stapled anastomosis after ileostomy closure [13]. Based upon our current findings, a liquid diet is provided until normal passage is established in order to avoid small bowel obstruction in the early postoperative phase.

A difference in complication rate between the closure of a defunctioning ileostomy for a colorectal or coloanal anastomosis on the one hand and an IPAA on the other hand could not be demonstrated. Some authors have reported a 
Table 2 Comparison of patientand surgery-related factors for electively and acutely created stomas in 138 patients

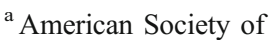
Anesthesiology

\begin{tabular}{lccc}
\hline Variables & Elective $(n=109)$ & Acute $(n=29)$ & $P$ value \\
\hline Gender & & & 0.443 \\
Male & $65(59.6)$ & $15(71.4)$ & \\
Female & $44(40.4)$ & & \\
Age (years) & & $48.4(20-79)$ & \\
Median (range) & $48.5(19-85)$ & $5(17.2)$ & 0.745 \\
ASA class & & $20(69.0)$ & \\
I & $26(23.9)$ & $4(13.8)$ & \\
II & $70(64.2)$ & $15(51.7)$ & \\
III & $13(11.9)$ & $7(24.1)$ & \\
Primary diagnosis & $52(47.4)$ & $7(24.1)$ & \\
Inflammatory bowel disease & $44(40.4)$ & - & \\
Colorectal cancer & $4(3.7)$ & $20(69.0)$ & \\
Familial adenomatous polyposis & $9(8.3)$ & $9(31.0)$ & \\
Other & & $22.3(7-69)$ & 0.062 \\
Type of primary surgery & $54(49.5)$ & & \\
Ileal pouch-anal anastomosis & $55(50.5)$ & & \\
Low colorectal anastomosis & $16.0(1-71)$ & & \\
Time to stoma closure (weeks) & & & \\
Median (range) & & & \\
\hline
\end{tabular}

Table 3 Complications and reoperations in 138 patients related to stoma closure

\begin{tabular}{lc}
\hline Complication & Number $(\%)$ \\
\hline Pneumonia & $5(3.6)$ \\
Lung embolism & $1(0.7)$ \\
Wound infection & $2(1.4)$ \\
Urinary tract infection & $5(3.6)$ \\
Cellulitis & $1(0.7)$ \\
Intraabdominal abscess & $3(2.2)$ \\
Anastomotic leakage & $6(4.3)$ \\
Small bowel obstruction & $9(6.5)$ \\
Dehydration & $3(2.2)$ \\
Readmission within 30 days & $5(3.6)$ \\
Enterocutaneous fistula & $1(0.7)$ \\
Abdominal wall bleeding & $1(0.7)$ \\
Jejunal perforation & $1(0.7)$ \\
Multi-organ failure & $1(0.7)$ \\
Perforation of the primary anastomosis & $1(0.7)$ \\
Stenosis of the small bowel anastomosis & $1(0.7)$ \\
Total & 46 complications in \\
Reoperation & $28(20.3 \%)$ patients \\
Ileostomy & \\
Relaparotomy (second look) & $8(5.8 \%)$ \\
Evacuation of a hematoma & $4(2.9 \%)$ \\
Enterocutaneous fistula closure & $1(0.7 \%)$ \\
Debridement & $1(0.7 \%)$ \\
Adhesiolysis & $1(0.7 \%)$ \\
Stoma revision & $1(0.7 \%)$ \\
Total & $1(0.7 \%)$ \\
\hline & $(8.0 \%)$ patients \\
\hline
\end{tabular}

higher morbidity after ileostomy closure associated with restorative proctocolectomy in comparison with (low) anterior resection [14]. It has been suggested that extensive dissection and mobilization during restorative proctocolectomy are resulting in adhesion formation [15]. We hypothesized that the traction on the mesentery and its reduced length in the case of an IPAA probably make mobilization and exposure during closure of the ileostomy more difficult. Regarding these observations, it is important to notice that one-stage IPAA is considered a safe procedure in selected patients and comparable to IPAA with a temporary ileostomy with respect to septic complications and pouch function [16]. One-stage IPAA avoids the impaired quality of life, morbidity, and medical costs associated with a defunctioning ileostomy.

The present analysis also includes defunctioning ileostomies that were created in an acute setting to treat anastomotic-related complications. To our knowledge, there are no other series of ileostomy closure reporting on this specific topic. Closure of the acutely created ileostomies was not associated with increased morbidity in spite of a longer period to stoma closure. Therefore, we would recommend the use of a defunctioning ileostomy for treatment of anastomotic leakage if considered appropriate. The $90 \%$ closure rate of our acutely created stomas demonstrates the success rate of this approach.

There are some limitations in the interpretation of the provided data. First of all, there are inherent methodological drawbacks because of the retrospective study design, although the complications were prospectively collected. In addition, the group of patients is heterogeneous as patients undergoing (low) anterior resection and proctocolectomies for both benign 
Table 4 Patient- and surgeryrelated risk factors for complications after stoma closure in 138 patients
${ }^{\mathrm{a}}$ American Society of Anesthesiology

\begin{tabular}{|c|c|c|c|}
\hline Variables & Noncomplicated $(n=110)$ & Complicated $(n=28)$ & $P$ value \\
\hline Gender & & & 0.106 \\
\hline Male & $60(54.5)$ & $20(71.4)$ & \\
\hline Female & $50(45.5)$ & $8(28.6)$ & \\
\hline Age (years) & & & 0.025 \\
\hline Median (range) & $46.8(20-85)$ & $55.1(19-82)$ & \\
\hline $\mathrm{ASA}^{\mathrm{a}}$ class & & & 0.012 \\
\hline I & $27(24.5)$ & $4(14.3)$ & \\
\hline II & $74(67.3)$ & $16(57.1)$ & \\
\hline III & $9(8.2)$ & $8(28.6)$ & \\
\hline Primary diagnosis & & & 0.307 \\
\hline Inflammatory bowel disease & $57(51.8)$ & $10(35.7)$ & \\
\hline Colorectal cancer & $37(33.6)$ & $14(50)$ & \\
\hline Familial adenomatous polyposis & $8(7.3)$ & $3(10.7)$ & \\
\hline Other & $8(7.3)$ & $1(3.6)$ & \\
\hline Type of primary surgery & & & 0.667 \\
\hline Ileal pouch-anal anastomosis & $60(54.5)$ & $14(50.0)$ & \\
\hline Low colorectal anastomosis & $50(45.5)$ & $14(50.0)$ & \\
\hline Setting of stoma creation & & & 0.562 \\
\hline Elective (prophylactic) & $88(80.0)$ & $21(75.0)$ & \\
\hline Acute (anastomotic complications) & $22(20.0)$ & $7(25.0)$ & \\
\hline Surgeon & & & 0.130 \\
\hline Resident & $101(91.8)$ & $23(82.1)$ & \\
\hline Colorectal surgeon & $9(8.2)$ & $5(17.9)$ & \\
\hline Time to stoma closure (weeks) & & & 0.611 \\
\hline Median (range) & $16.6(1-70)$ & $19.6(1-71)$ & \\
\hline Anastomotic technique & & & 0.183 \\
\hline Hand-sewn & $100(90.9)$ & $23(82.1)$ & \\
\hline Stapled & $10(9.1)$ & $5(17.9)$ & \\
\hline
\end{tabular}

and malignant diseases were included. Nevertheless, this analysis reflects the quality of defunctioning ileostomy closure in an academic tertiary referral center.

A defunctioning stoma decreases the clinical leak rate and reoperation rate and is therefore recommended after low anterior resection and restorative proctocolectomy with IPAA $[1,3]$. Unfortunately, randomized trials on the clinical impact of defunctioning ileostomy choose anastomotic leakage as primary endpoint, and complications after stoma closure are often not included in the overall analysis [17]. Furthermore, ileostomy closure is not counted as a reoperation in these trials, because it was a planned procedure. This is questionable given its clinical impact and associated cost.

The currently available data cannot provide clear guidelines regarding which anastomosis should be primarily diverted based on the overall complication rate. Of course, several risk factors for anastomotic leakage have been identified, but the complications related to stoma closure are not properly weighed against the reduced leakage rate $[2,18]$. The present study suggests that selective use of a defunctioning ileostomy after low rectal or anal anastomosis is justified. If there is any sign of leakage of the undiverted anastomosis in the early postoperative course, a secondary defunctioning ileostomy can be constructed in the acute setting. These stomas have a high closure rate and are not associated with an increased complication rate as is demonstrated by our analysis. Further studies should focus on selection criteria by which an optimal balance between advantages and disadvantages of primary diversion can be achieved.

In conclusion, closure of a defunctioning ileostomy is associated with $20 \%$ morbidity and a reoperation rate of $8 \%$. The only risk factor after multivariate analysis for a complicated course was ASA score, but no impact could be demonstrated for type of anastomosis or the acute setting. Based upon these results, a secondary ileostomy for the treatment of anastomotic complications seems to be a valid option. The significant morbidity of stoma closure appeals for a combined endpoint including these complications in further studies on defunctioning ileostomies.

Open Access This article is distributed under the terms of the Creative Commons Attribution Noncommercial License which permits any noncommercial use, distribution, and reproduction in any medium, provided the original author(s) and source are credited. 


\section{References}

1. Huser N, Michalski CW, Erkan M, Schuster T, Rosenberg R, Kleeff J et al (2008) Systematic review and meta-analysis of the role of defunctioning stoma in low rectal cancer surgery. Ann Surg 248:52-60

2. Sagap I, Remzi FH, Hammel JP, Fazio VW (2006) Factors associated with failure in managing pelvic sepsis after ileal pouchanal anastomosis (IPAA)-a multivariate analysis. Surgery 140:691-703

3. Tan WS, Tang CL, Shi L, Eu KW (2009) Meta-analysis of defunctioning stomas in low anterior resection for rectal cancer. $\mathrm{Br}$ J Surg 96:462-472

4. Mala T, Nesbakken A (2008) Morbidity related to the use of a protective stoma in anterior resection for rectal cancer. Colorectal Dis 10:785-788

5. Nastro P, Knowles CH, McGrath A, Heyman B, Porrett TR, Lunniss PJ (2010) Complications of intestinal stomas. Br J Surg 97:1885-1889

6. Chow A, Tilney HS, Paraskeva P, Jeyarajah S, Zacharakis E, Purkayastha S (2009) The morbidity surrounding reversal of defunctioning ileostomies: a systematic review of 48 studies including 6,107 cases. Int J Colorectal Dis 24:711-723

7. den Dulk DM, Smit M, Peeters KC, Kranenbarg EM, Rutten HJ, Wiggers $\mathrm{T}$ et al (2007) A multivariate analysis of limiting factors for stoma reversal in patients with rectal cancer entered into the total mesorectal excision (TME) trial: a retrospective study. Lancet Oncol 8:297-303

8. Akiyoshi T, Fujimoto Y, Konishi T, Kuroyanagi H, Ueno M, Oya $\mathrm{M}$ et al (2010) Complications of loop ileostomy closure in patients with rectal tumor. World J Surg 34:1937-1942
9. Giannakopoulos GF, Veenhof AA, van der Peet DL, Sietses C, Meijerink WJ, Cuesta MA (2009) Morbidity and complications of protective loop ileostomy. Colorectal Dis 11:609-612

10. Williams LA, Sagar PM, Finan PJ, Burke D (2008) The outcome of loop ileostomy closure: a prospective study. Colorectal Dis $10: 460-464$

11. Mansfield SD, Jensen C, Phair AS, Kelly OT, Kelly SB (2008) Complications of loop ileostomy closure: a retrospective cohort analysis of 123 patients. World J Surg 32:2101-2106

12. Shelygin YA, Chernyshov SV, Rybakov EG (2010) Stapled ileostomy closure results in reduction of postoperative morbidity. Tech Coloproctol 14:19-23

13. Leung TT, MacLean AR, Buie WD, Dixon E (2008) Comparison of stapled versus handsewn loop ileostomy closure: a metaanalysis. J Gastrointest Surg 12:939-944

14. van de Pavoordt HD, Fazio VW, Jagelman DG, Lavery IC, Weakley FL (1987) The outcome of loop ileostomy closure in 293 cases. Int J Colorectal Dis 2:214-217

15. Wong KS, Remzi FH, Gorgun E, Arrigain S, Church JM, Preen M et al (2005) Loop ileostomy closure after restorative proctocolectomy: outcome in 1,504 patients. Dis Colon Rectum 48:243-250

16. Remzi FH, Fazio VW, Gorgun E, Ooi BS, Hammel J, Preen M et al (2006) The outcome after restorative proctocolectomy with or without defunctioning ileostomy. Dis Colon Rectum 49:470-477

17. Matthiessen P, Hallbook O, Rutegard J, Simert G, Sjodahl R (2007) Defunctioning stoma reduces symptomatic anastomotic leakage after low anterior resection of the rectum for cancer: a randomized multicenter trial. Ann Surg 246:207-214

18. Peeters KC, Tollenaar RA, Marijnen CA, Klein KE, Steup WH, Wiggers $\mathrm{T}$ et al (2005) Risk factors for anastomotic failure after total mesorectal excision of rectal cancer. Br J Surg 92:211-216 